\title{
Mikro Besin Takviyesinin Maternal-Fetal Sonuçlara Etkisi: D vitamini, Kalsiyum ve Magnezyum
}

Effects of Micronutrient Supplement on Maternal and Fetal Outcomes: Vitamin D, Calcium and Magnesium

\section{Ozan DOĞAN ${ }^{1}$, Aşkı Ellibeş KAYA ${ }^{2}$, Çiğdem PULATOĞLU ${ }^{3}$, Bertan AKAR ${ }^{4}$, Alper BAŞBUĞ ${ }^{2}$, Eray ÇALIŞKAN ${ }^{5}$}

1. Şişli Hamidiye Etfal Eğitim ve Araştırma Hastanesi, Kadın Hastalıkları ve Doğum Kliniği, İstanbul, Türkiye

2. Düzce Üniversitesi Tıp Fakültesi, Kadın Hastalıkları ve Doğum Kliniği, Düzce, Türkiye

3. Bayburt Devlet Hastanesi, Kadın Hastalıkları ve Doğum Kliniği, Bayburt, Türkiye

4. İstinye Üniversitesi Tıp Fakültesi, Kadın Hastalıkları ve Doğum Kliniği, İzmit, Türkiye

5. Bahçeşehir Üniversitesi Tıp Fakültesi, Kadın Hastalıkları ve Doğum Kliniği, İmit, Türkiye

\section{$\ddot{O Z Z E T}$}

Amaç: Fetal ve maternal sağlığa olumlu etkileri olması nedeniyle gebelik döneminde artan ihtivaçla orantılı olarak vitamin ve mineral desteğine ihtiyaç vardır. Bu çalışmada mikro besin takviyesi olarak D vitamini, Kalsiyum (Ca) ve Magnezyum $(\mathrm{Mg})$ desteği alan gebelerin postnatal sonuçlarını ve gebelik komplikasyonlarını araştırmak amaçlandı.

Gereçler ve Yöntem: Yapılan bu prospektif, longitudinal ve kalitatif çalısmaya Ocak 2016 ve Ocak 2018 tarihleri arasinda 18-40 yaş arası toplam 2114 hasta dahil edilmiştir.

Bulgular: Maternal yaş aralığl tüm hasta gruplarl için 28.11 $\pm 6.12^{\prime}$ dir. Multivitamin kullanan grubun yaş ortalaması D vitamini grubuna göre daha düsük saptandl $(p=0.001)$. Yalnızca $M g$ ve D vitamini kullanan grupta yüksek lisans seviyesinde eğitim görenler daha fazlaydl( $p=0.001) . \mathrm{Mg}, \mathrm{Ca}, \mathrm{D}$ vitamini ve multivitamin kullananımı ile gebelik komplikasyonları arasında anlamlı iliski bulunamadt. Multivitamin kullanan gebelerde $L G A$ daha fazla görüldü $(p=0.038)$. Illk gebelik yaşı Ca ve mulivitamin kullanan grupta Mg ve D vitamini kullanan gruba göre daha düsük bulunmuștur( $p=0.001)$.

Sonuç: Annenin sağlıklı bir gebelik geçirmesi, maternal komplikasyonlardan korunması, fetusun büyüme ve gelişmesi için annenin düzenli beslenmesinin yanı stra vitamin ve mineral takviyesi önemlidir. Bu takviyelerin literatürde gösterilmiş olan yararlarını desteklemek ve rutin kullanımda yer vermek için daha çok prospektif çalıșmaya ihtiyaç vardır.

Anahtar Kelimeler: D vitamini, kalsiyum, gebelik, magnezyum, mikro besin takviyesi

\section{ABSTRACT}

Objective: Due to the positive effects on fetal and maternal health, there is an increased need for vitamin and mineral supplements during pregnancy. In this study, it was aimed to investigate the postnatal outcomes and pregnancy complications of pregnant women who received vitamin D supplementation, calcium (Ca) and magnesium (Mg) as micronutrient supplement.

Material and Methods: A total of 2114 patients aged between 18 and 40 years were included in this prospective, longitudinal and qualitative study between January 2016 and January 2018

Results: The mean maternal age was $28.11 \pm 6.12$ for all patient groups. The mean age of the group received multivitamins was lower than the vitamin D group $(p=0.001)$.

İletişim Bilgileri

Sorumlu Yazar: Ozan DOĞAN

Yazışma Adresi: Şişli Hamidiye Etfal Eğitim ve Araştırma Hastanesi, Kadın Hastalıkları ve Doğum Kliniği, İstanbul, Türkiye E-posta: ozandogan02@hotmail.com

Tel: +90 (505) 5060720

Makale Geliş Tarihi: 19.08.2018

Makale Kabul Tarihi: 03.09.2018

DOI: http://dx.doi.org/10.16948/zktipb.454539
In the group receiving only $M g$ and vitamin D supplements, the number of postgraduate educated patients were more ( $p$ $=0.001)$. There was no significant relationship between $\mathrm{Mg}$, $C a$, vitamin $D$ and multivitamin use and pregnancy complications. LGA was more frequent in multivitamin-using group ( $p=$ 0.038). The first gestational age was found to be lower in $\mathrm{Ca}$ and multivamine group compared to the group receiving $\mathrm{Mg}$ and vitamin D supplement $(p=0.001)$.

Conclusion: Vitamin and mineral supplementation as well as the regular daily nutrition is important not only for women to have a healthy pregnancy period without any maternal complications but also for growth and development of the fetus. More prospective studies with larger population are needed for supporting the benefits of these supplements and suggest their routine usage.

Keywords: vitamin D, calcium,pregnancy, magnesium, micronutrition supplementation

\section{GİRIŞ}

Gebelik ve emzirme gibi enerji ihtiyacının arttığı dönemlerde önemli mikro besin öğelerine de ihtiyac artmaktadır (1). Bu süreçte pek çok hasta mikro besin ihtiyaçlarını tek bașına beslenme ile karşılayamaz ve profesyonel bir desteğe ihtiyaç duyar. Gebe kadınlarda çoklu mikro besin takviyeleri, maternal beslenme ve bağışıklık durumunun iyileştirilmesi yoluyla istenmeyen gebelik sonuçlarını azaltmaya yönelik yararları kanıtlanmış destekleyici tedavilerdir $(2,3)$.

$\mathrm{Bu}$ çalışmada mikro besin takviyesi olarak D vitamini, Kalsiyum (Ca) ve Magnezyum ( $\mathrm{Mg}$ ) desteği alan gebelerin postnatal sonuçlarını ve gebelik komplikasyonlarını araştırmak amaçlandı.

\section{D vitamini}

Gebelik sırasında plasental implantasyon, anjiyogenez, immün fonksiyon, oksidatif stres, endotelyal fonksiyon, inflamatuar yanit ve glukoz homeostazisi üzerindeki etkileri nedeniyle D vitaminine artan bir ilgi vardır (4). D vitamini eksikliği istenmeyen gebelik sonuçlarıyla ilişkilendirilmiş tüm dünyada yaygın görülen bir durumdur (5). D vitamininin dolaşımdaki ana formu olan 25(OH)D'nin düşük düzeylerinin tekrarlayan gebelik kayıpları, preeklampsi, gestasyonel diyabet, maternal enfeksiyonlar, preterm doğum ve düşük doğum ağırlığı ile ilişkili olduğu düşünülmektedir (6). 
Günlük D vitamini gereksinimi konusunda ülkeler ve kuruluşlar arasında farklı öneriler bulunmakta olup henüz görüş birliğine ulaşılmış değildir. 2010 y1linda Institute of Medicine (IOM) gebelik ve laktasyon döneminde günde 600 IU D vitamini alınmasını ve tolere edilebilir üst limiti 4000 IU olarak önermektedir (3). ACOG gebelikte D vitamini eksikliği saptandığında da 1000-2000 IU/gün dozunda $\mathrm{D}$ vitamini desteği verilmesinin uygun olacağ 1 , daha yüksek dozların zararlı olup olmadığı konusunda çalışmalara gereksinim olduğu rapor edilmektedir (1). Ülkemizde gebelere D vitamini destek programı 2011 yılı itibari ile başlamıştır. D vitamini kullanmasında sakınca olan hastalar dışında ayrım yapılmaksızın tespit edilen tüm gebelere gebelik süresince ve doğum sonrası altı ay olmak üzere D vitamini desteği günlük tek doz olarak alınmak üzere 1200 IU önerilmektedir (7). Gebelikte optimum D vitamini seviyesi bilinmemektedir ve hala araştırılmaktadir (1).

\section{Kalsiyum}

Kas fonksiyonuna, kan damar dinamiğine, sinir dürtü iletimine, hormonların salgılanmasına, kan pıhtılaşmasına, hücre zarı fonksiyonlarına ve iskelet gelişimine aracılık etmede önemli rollere sahiptir (8). Normal kan pıhtılaşması, hücre zarı fonksiyonları, optimal $\mathrm{Ca}$ emilimi ve iskeletin gelişimi için Ca gereklidir (8). Fetus, kemik gelişimi ve dokuların büyümesi, fonksiyon kazanabilmesi için gerekli olan kalsiyum bakımından tamamen anneye bağımlıdır (9). Gebelik boyunca fetal kalsiyum ihtiyacı 30 g'dır ve bunun \%80'i üçüncü trimesterdadır. Artan bu talebi karşılamak için barsakta kalsiyum emilimi hamilelik sırasında iki kattan fazladır (8). Epidemiyolojik ve klinik çalışmalar, gebelikte kalsiyum alımı ve hipertansiyon gelişimi arasında ters bir ilişki olduğunu göstermiştir (10).

\section{Magnezyum}

Büyük miktarlarda ihtiyaç duyulan esansiyel minerallerden biridir. Vücut 1sısın1, sinir ve kas membranlarındaki elektrik potansiyelini korumas1nın yanı sıra nükleik asit ve protein sentezinde de görevlidir (11). Nörolojik fonksiyonları düzenleme, kardiyak uyarım ve müsküler kontraksiyon ve vasküler tonusu düzenlemede de rol almaktadır (12). Yeşil sebzelerde ve tahillarda bulunmasına rağmen özellikle düşük gelirli bölgelerde Mg eksikliği yaygındır. Kadınlar ve adölesanlarda Mg eksikliğine yatkınlık olduğundan $\mathrm{Mg}$ alımı günde $280 \mathrm{mg}$ olarak tavsiye edilmekte olup gebelikte artırılması önerilmiştir (13). Gebelikte Mg eksikliği, artmış kronik hipertansiyon riski, preeklampsi, plasental disfonksiyon ve prematüre doğum riski ile ilişkili bulunmuştur (14).

Gebelikte Mg takviyesi preeklampsi, preterm doğum, gestasyonel diyabet, bacaklarda kramp, doğum ağırlığı, apgar skoru üzerinde olumlu etkiye sahiptir (15). Düşük riskli gebelerde serum $\mathrm{Mg}$ seviyesini ölçen bir çalışma, hem iyonize hem de total serum Mg seviyesinin 18. gebelik haftasindan sonra bu zamana kadar olan ölçümlerle karşılaştırıldığında önemli ölçüde azaldığını bildirmiştir (16).

\section{GEREÇ ve YÖNTEM}

Yap1lan bu prospektif, longitudinal ve kalitatif çalışmaya Ocak 2016 ve Ocak 2018 tarihleri arasında 18-40 yaş arası toplam 2114 hasta dahil edilmiştir. Çalışmaya katılmayı kabul eden tüm hastalardan yazılı aydınlatılmış onam alındı. Tüm katılımcılar 56 standart maddeden oluşan ve Türk Jinekoloji ve Obstetrik Derneği (TSOG) tarafından oluşturulan kapsamlı mikro besin araştırması anketini tamamladı. Çalışmadaki tüm prosedürler, 1964 Helsinki Deklarasyonu Kurumsal Araştırma Komitesi'nin etik standartlara uygun olarak gerçekleştirilmiştir ve yerel etik komite izni almıştır.

Tek canlı doğum yapan kadınlar çalışmaya dahil edildi. Dahil edilememe kriterleri çoğul gebelikler, sigara kullanımı, çalışma sırasında aktif hastalıkları olan, fetal kromozomal veya yapisal anomalisi olan, maternal kronik hipertansiyonu, hipo-hipermagnezemi, hipo-hiperkalsemi veya bunlara yol açabilen hipo-hiperparatiroidisi olan hastalar dahil edilmemiştir.

\section{Çalışma Popülasyonu}

Datalar kadın hastalıkları polikliniklerinin rutin tarama programina kayıtlı toplam 2114 gebeden (413 gebe magnezyum, 520 gebe kalsiyum, 563 gebe D vitamini, 618 gebe de multivitamin kullanıldı) elde edilmiştir. Tüm hastaların yaş, gravida, parite, abortus say1s1, son adet tarihi, USG'ye göre gebelik haftaları, son mensturasyon tarihi, boy, kilo ve vücut kitle indeksi (VKİ) kaydedildi. VKİ, aşağıdaki formül kullanılarak hesaplanmıştır: ağırlık (kg) / yükseklik2 (m). Eğitim ve gelir, tüm katılımcılar için iki temel sosyoekonomik durum göstergesiydi. Kişi başına aylık gelirlerine göre, Mart 2018'de düşük (<1500 TL), orta (1500-3000 TL) ve yüksek (> 3000 TL) [1 ABD Doları = 3.75 Türk Lirası (TL)] olarak sınıflandırılmıştır.

Tüm katılımc1 gebelerin rutin doğum öncesi kontrolleri yapıldı. Hastalar ilk trimesterden başlayarak her trimesterde en az bir kez değerlendirildi. Gestasyonel diabetes mellitus (GDM) ve pre-eklampsi gibi gebelikle ilişkili komplikasyonların varlığ1 değerlendirildi. GDM taramas1, Dünya Sağlik Örgütü'nün önerilerine göre gerçekleştirildi (17). Preeklampsi, daha önce normotansif kadınlarda 20. Gebelik haftasından sonra sistolik kan basincı > $140 \mathrm{mmHg}$ veya diyastolik kan basinc1> $90 \mathrm{mmHg}$ olması ve proteinüri (İdrar tahlilinde $100 \mathrm{mg} / \mathrm{dL}$ veya 24 saatlik idrarda $300 \mathrm{mg}$ ) olarak tanımlandı (18). Preterm doğum, doğumda gestasyon yaş1, doğum ağırlı̆̆1(g) ve doğum sonu kanama gibi perinatal veriler topland1. Preterm doğum, <37 gebelik haftasinda tamamlanan gebelik olarak tanımlandi. Gardosi ve ark.nın formüllerine göre hesaplanan doğum ağırlığı Z-skorları kullanılarak 10. Persentil altına SGA 90. persentil üstüne LGA denildi (19).

$\mathrm{Bu}$ çalışmada; gebelerin vitamin ve mineral desteğinin maternal kilo alımı, fetusların doğum kiloları (gebelik yaşına göre düşük doğum ağırlığı (SGA), gebelik yaşına göre büyük doğum ağırlığ1 (LGA)), 
gebelik komplikasyonları (preeklampsi, gestasyonel diabetes mellitus (GDM), postpartum hemoraji), mikro besin takviyelerinin kullanım süresi ve preterm doğumlara olan etkileri araştırıldı. Ayrıca hastaların sosyokültürel-ekonomik düzeyleri ve maternal yaşın mikro besin takviyesi kullanımıyla ilişkisi incelendi.

\section{İstatistiksel Analiz}

Sürekli değişkenler için tanımlayıcı istatistikler ortalama \pm standart sapma veya ortanca (minimum maksimum) olarak ifade edildi ve nominal değişkenler sayı ve yüzde (\%) olarak ifade edildi. Her bir grup için ortalama değerler Student t-testi kullanılarak ve medyan değerler Mann-Whitney U-testi kullanılarak değerlendirildi. Kategorik veriler, Ki-kare kullanılarak değerlendirildi ve 0.05 den küçük p değerleri, istatistiksel olarak anlamlı kabul edildi. İstatistiksel analiz, SPSS for Windows sürüm 22 (SPSS, Inc., Chicago, IL, ABD) kullanılarak yapıldı.

\section{BULGULAR}

Maternal yaş aralığ $28.11 \pm 6.12^{\prime}$ dir. $\mathrm{Mg}$ kullanan 413 gebenin, Ca kullanan 520 gebenin, D vitamini kullanan 563 gebenin ve ve multivitamin takviyesi alan 618 gebenin yaş ortalaması sırasıyla $28.03 \pm 6.12,26.70 \pm 5.27$, $28.11 \pm 5.86,26.45 \pm 5.22$ idi. Multivitamin kullanan grubun yaş ortalaması $\mathrm{D}$ vitamini grubuna göre daha düşük saptandı ( $\mathrm{P}=0.001$ ).
Eğitim durumlarına göre incelendiğinde Mg kullanan 413 gebeden $22(\% 5,3)$ 'si ve D vitamini kullanan 563 gebeden $28(\% 5,0)$ 'i yüksek lisans mezunuydu ve yalnızca $\mathrm{Mg}$ ve D vitamini kullanan grupta yüksek lisans seviyesinde eğitim görenler daha fazlayd 1 ( $\mathrm{P}=0.001)$. Ekonomik düzeylerine göre incelendiğinde ise yalnızca Ca kullanımı olan 520 gebeden 75 (\%14.5)'inin gelir düzeyi yüksekti ve sadece bu grupta gelir düzeyi ile takviye mikro besin kullanımı arasında istatistiksel anlamlı fark saptand1 $(P=0.003)$. Her dört grubun ilk gebelik yaşlarına göre vitamin ve mineral kullanımı incelendiğinde $\mathrm{Mg}$ kullanan gebelerin, Ca kullanan gebelerin, D vitamini kullanan gebelerin ve multivitamin desteği alan gebelerin ilk gebeliklerinin yaş ortalaması sırasılyla $27.42 \pm 9.99,18.78 \pm 11.63$, $25.35 \pm 11.08$ ve $17.99 \pm 11.31$ idi. İlk gebelik yaş1 Ca ve mulivitamin kullanan grupta $\mathrm{Mg}$ ve D vitamini kullanan gruba göre daha düşük bulunmuştur. $(\mathrm{P}=0.001)$ (Tablo 1).

Obstetrik öykü incelemesinde 2114 gebeden hiç birinin daha önce abort öyküsü yoktu, daha önce bir kez doğum yapmışlardı. Gruplar arası mikro besin takviyelerin kullanım süresi açısından değerlendirildiğinde yalnızca D vitamini kullanan grubun kullanım süresi $4.81 \pm 1.19$ idi. Diğer gruplara göre istatistiksel olarak anlamlıyd 1 ve daha az kullandikları saptand $(\mathrm{P}=0.003)$. Gebelik boyunca en az kilo alımı Mg kullanan gruptaydı ve $6.95 \pm 4.31 \mathrm{~kg}$ olarak bulundu, diğer grupların kilo alımları ise;

Tablo 1: Mikro besin takviyesine göre sosyodemografik özlellikleri.

\begin{tabular}{|c|c|c|c|c|c|}
\hline & $\begin{array}{c}\text { Mg Takviyesi } \\
(n=413)\end{array}$ & $\begin{array}{l}\text { Ca Takviyesi } \\
(n=520)\end{array}$ & $\begin{array}{l}\text { D vitamini } \\
\text { Takviyesi; } \\
(n=563)\end{array}$ & $\begin{array}{l}\text { Multivitamin } \\
\text { Takviyesi } \\
(\mathrm{n}=618)\end{array}$ & $\stackrel{P}{\text { değerleri }}$ \\
\hline Anne yaşı (yıl) & $28.03 \pm 6.12$ & $26.70 \pm 5.27$ & $28.11 \pm 5.86^{*}$ & $26.45 \pm 5.22 *$ & 0.001 \\
\hline Gravida & $2(1-8)$ & $2(1-9)$ & $2(1-8)$ & 2.(1-9) & 0.178 \\
\hline Parite & $1(0-5)$ & $1(0-4)$ & $1(0-5)$ & $1(0-4)$ & 0.237 \\
\hline VKi & $27.08 \pm 4.82$ & $27.55 \pm 5.13$ & $27.24 \pm 4.42$ & $26.94 \pm 5.21$ & 0.717 \\
\hline Abortus öyküsü & $0(0-2)$ & $0(0-5)$ & $0(0-2)$ & $0(0-5)$ & 0.639 \\
\hline \multicolumn{6}{|l|}{ Eğitim Seviyesi } \\
\hline \multicolumn{6}{|l|}{ Okur-yazar değil } \\
\hline & $48(1.6 \%)$ & $72(13.8 \%)$ & 47 (8.5\%) & 73 (11.7\%) & 0.051 \\
\hline \multicolumn{6}{|l|}{ İlkokul } \\
\hline & $108(26.2 \%)$ & $122(23.5 \%)$ & $147(26.1 \%)$ & $142(23.0 \%)$ & 0.481 \\
\hline \multicolumn{6}{|l|}{ Ortaokul } \\
\hline & $100(24.2 \%)$ & $154(20.6 \%)$ & $168(29.8 \%)$ & $188(30.4 \%)$ & 0.140 \\
\hline \multicolumn{6}{|l|}{ Lise } \\
\hline & $95(23.0 \%)$ & 119 (22.9\%) & $122(21.7 \%)$ & $138(22.3 \%)$ & 0.954 \\
\hline \multicolumn{6}{|l|}{ Üniversite } \\
\hline & $40(9.7 \%)$ & $43(8.3 \%)$ & $49(8.7 \%)$ & $66(10.7 \%)$ & 0.506 \\
\hline \multicolumn{6}{|c|}{ Yüksek lisans mezunu } \\
\hline & $22(5.3 \%)^{*}$ & $10(1.9 \%)$ & $28(5.0 \%)^{*}$ & $12(1.9 \%)$ & 0.001 \\
\hline \multicolumn{6}{|l|}{ Gelir } \\
\hline Düşük & $112(27.2 \%)$ & $175(33.6 \%)$ & $101(17.9 \%)$ & $163(26.4 \%)$ & 0.667 \\
\hline \multirow[t]{2}{*}{ Orta } & $186(45.0 \%)$ & $270(51.9 \%)$ & $275(48.8 \%)$ & 311 (50.3\%) & 0.326 \\
\hline & & & $187(33.3 \%)$ & $144(23.3 \%)$ & 0.003 \\
\hline Yüksek & $115(28.7 \%)$ & $75(14.5 \%)^{*}$ & & & \\
\hline İlk gebelik yaşı & $27.42 \pm 9.99$ & $18.78 \pm 11.63^{*}$ & $25.35 \pm 11.08$ & $17.99 \pm 11.31 *$ & 0.001 \\
\hline
\end{tabular}


Ca kullananlarda $8.53 \pm 3.67 \mathrm{~kg}$, D vitamini kullananlarda $8.97 \pm 4.21 \mathrm{~kg}$, multivitamin kullanan gebelerde $9.92 \pm 3.55 \mathrm{~kg}$ 'd1. Mineral takviyesi kullanımıyla gebelik boyunca kilo alımı arasındaki ilişki magnezyum alan grupta istatistiksel olarak anlaml bulundu ( $\mathrm{P}=0.003)$ (Tablo 2).

Fetal açıdan Mg kullanan gebelerin çocuklarının doğum ağırlı̆ğ $2942 \pm 837$ idi. 413 gebeden $28(\% 6.7)$ 'i erken doğum, 30 (\%7.3)'u SGA, 23 (\%5.5)'ünde ise LGA saptandi. Kalsiyum kullanan 520 gebenin çocuklarının doğum ağırlığ $2727 \pm 829$ idi. Bu gebelerden 35 (\%6.8)'inde preterm doğum, 36 (\%6.9)'sında SGA, 32 (\%6.2)'sinde ise LGA saptand. D vitaminin kullanan 563 gebenin çocuklarının do-

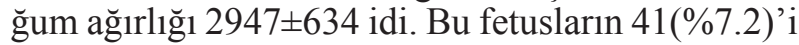
erken doğum, 40(\%7.1)'inda SGA, 33(\%5.9)'ünde ise LGA saptand. Multivitamin desteği alan 618 gebenin yeni doğanlarının kilosu $3055 \pm 416$ idi ve bu yeni doğanlardan $41(\% 6.6)$ 'i preterm doğum, 42 (\%6.8)'sinde SGA ve 62(\%9.9)'sinde ise LGA saptandı. İstatistiksel olarak multivitamin kullanımında LGA görülme oranında anlamlı farklılık izlendi $(\mathrm{P}=0.038)($ Tablo 2).

Gebelik komplikasyonları karşılaştırıldığında $\mathrm{Mg}$ kullananların 24(\%5.8)'ünde preeklampsi, 34 (\%8.3)'ünde GDM, 19 (\%4.7)'unda ise postpartum hemoraji görüldü, 336 gebede herhangi bir maternal komplikasyon izlenmedi. Ca kullanan 520 gebenin 25 (\%4.6)'inde preeklampsi, 40 (\%7.6)'inda GDM, 22 (\%4.2)'sinde postpartum hemoraji görüldü. D vitamini kullanan 563 gebenin $26(\% 4.7)$ 'sinda preeklampsi, 32 (\%5.7)'sinde GDM, 26 (4.\%6)'sinda postpartum hemoraji izlenirken multivitamin desteği alan hastaların 43 (\%6.9)'ünde preeklampsi, 57 (\%9.3)'sinde GDM, 42 (\%6.8)'sinde postpartum kanama görüldü. İstatistiksel olarak maternal komplikasyonlarla vitamin ve mineral desteği arasinda anlamlı farklılık saptanmadı (Tablo 2).

\section{TARTIŞMA}

Fetal ve maternal sağlığa olumlu etkileri olması nedeniyle gebelik döneminde artan ihtiyaçla orantılı olarak vitamin ve mineral desteğine ihtiyaç vardır. Annenin yetersiz beslenmesi dünya genelinde halk sağlığında en çok ihmal edilen faktörlerden biri olarak tanımlanmıştır (20). Bu çalışmada mikro besin takviyesinin gebelik komplikasyonlarına ve postnatal sonuçlar üzerine olumlu etkisi olmadığ1 görülmüştür. Multivitamin kullanan hastalarda LGA daha fazla görülmekle beraber yalnızca $\mathrm{Mg}$ kullanan gebelerde kilo alımı daha az saptandı. Ĕğitim seviyesine göre vitamin kullanımı çeşitlilik göstermektedir.

Yetersiz beslenme ve hastalıklar dolaylı olarak maternal, fetal ve neonatal beslenme durumunu etkilese de bunun yanında ilk gebelik yaşı ve tekrarlayan gebelikler de önemli faktörlerdir (21). Fiziksel olgunluğa ulaşmamış genç kızlar gebeliklerinde tükenmiş besin rezervi, anemi ve diğer mikro besin eksiklikleriyle sıklıkla karşılaşmaktadırlar (22). $\mathrm{Bu}$ çalışmada da ilk gebelik yaşı Ca ve mulivitamin kullanan grupta $\mathrm{Mg}$ ve $\mathrm{D}$ vitamini kullanan gruba göre daha düşük bulunmuştur.

Preterm doğum perinatal mortalite ve morbiditenin önde gelen sebeplerindendir ve bazı gelişmiş ülkelerde de insidansı artmaktadır (23). Mg preterm uterin kasılmalarını $\mathrm{Ca}$ antagonizması yoluyla yaptığ 1 düşünülmektedir ve elli yılı aşkın süredir de tokolitik ajan olarak kullanılmaktadır (24). Mg kullanımı ile preterm doğum arasındaki ilişkide yapılan çalışmalar arasında çelişkiler bulunmaktadır. 37 haftadan önce doğum yapan kadınlarla miadında doğum yapan kadınların karşılaştırıldığ 1 birkaç çalışmada preterm doğum öyküsü olanların serum $\mathrm{Mg}$ düzeyleri anlamlı olarak düşük bulunmuştur (25). Buna karşılık Tayvanlı gebelerde yapılan prospektif bir çalışmada erken doğuranlarla miad doğuran kadınlar arasında serum Mg düzeyi ve Mg alımı arasında fark bulunmamamıştır (26). Bu çalışmada Mg kullanımı ile preterm doğum arasında istatistiksel olarak ilişki saptanmamıştır.

Günde 600 mg'dan az Ca tüketen ve ek Ca (1.500 $\mathrm{mg} /$ gün) ile takviye edilen gebeler arasında, preterm doğum riskinde azalma gözlenmiştir (27). 2006 y1linda yapilan Cochrane derlemesinde besinlerle aldıği kalsiyumu az olan fakat günlük $1000 \mathrm{mg} \mathrm{Ca}$ desteğini dışardan alan kadınların preterm doğum riskini \%24 azaldığ 1 gözlenmiştir (28). 2015 yılında yapılan, 23 çalışmanın gözden geçirildiği, 17842 gebenin analiz edildiği Cochrane derlemesinde ise

Tablo 2: Mikro besin takviyesine göre postnatal sonuçlar, maternal komplikasyonlar ve obstetrik öykü.

\begin{tabular}{|c|c|c|c|c|c|}
\hline & $\begin{array}{l}\text { Mg Takviyesi } \\
\qquad(n=413)\end{array}$ & $\begin{array}{l}\text { Ca Takviyesi } \\
\qquad(n=520)\end{array}$ & $\begin{array}{l}\text { D vitamin Takviyesi } \\
\qquad(n=563)\end{array}$ & $\begin{array}{c}\text { Multivitamin } \\
\text { Takviyesi }(n=618)\end{array}$ & $\mathrm{P}$ değerleri \\
\hline Takviye süresi (hafta) & $8.01 \pm 1,98$ & $9.14 \pm 2,03$ & $4.81 \pm 1.19 *$ & $8.47 \pm 1.56$ & 0.003 \\
\hline Gebelikte kilo alımı (kg) & $6.95 \pm 4.31 *$ & $8.53 \pm 3.67$ & $8.97 \pm 4.21$ & $9.92 \pm 3.55$ & 0.003 \\
\hline Erken doğum & $28(6.7 \%)$ & $35(6.8 \%)$ & $41(7.2 \%)$ & $41(6.6 \%)$ & 0.824 \\
\hline Yenidoğan ağırlığı (g) & $2942 \pm 837$ & $2727 \pm 829$ & $2947 \pm 634$ & $3055 \pm 416$ & 0.272 \\
\hline SGA & $30(7.3 \%)$ & $36(6.9 \%)$ & $40(7.1 \%)$ & $42(6.8 \%)$ & 0.812 \\
\hline LGA & $23(5.5 \%)$ & $32(6.2 \%)$ & $33(5.9 \%)$ & $62(9.9 \%)^{*}$ & 0.038 \\
\hline \multicolumn{6}{|l|}{ Gebelik komplikasyonları } \\
\hline Preeklampsi & $24(5.8 \%)$ & $25(4.6 \%)$ & $26(4.7 \%)$ & $43(6.9 \%)$ & 0.303 \\
\hline Gestasyonel diyabet & $34(8.3 \%)$ & $40(7.6 \%)$ & $32(5.7 \%)$ & $57(9.3 \%)$ & 0.160 \\
\hline Postpartum kanama & $19(4.7 \%)$ & $22(4.2 \%)$ & $26(4.6 \%)$ & $42(6.8 \%)$ & 0.123 \\
\hline
\end{tabular}

VSGA: Gebelik yaşına göre düşük doğum ağırlığı, LGA: Gebelik yaşına göre büyük doğum ağılığı, Değerler ortalama \pm standart sapma, medyan (min-max) ve \% olarak verilmiştir. * $p<0.05$ istatistiksel anlamlılığı gösterir. 
Ca alan gebelerle almayanlar arasında preterm doğum açısından anlamlı istatistiksel farklılık saptanmamıştır (29). Dünya genelinde düşük gelir seviyesi olan ülkelerde yapılan meta-analizde çoklu mikro besin takviyesinin de preterm doğum üzerinde etkisi gösterilmemiştir (30). Bu çalışmada Ca kullanımı ile preterm doğum arasında istatistiksel olarak ilişki saptanmamıştır.

Multivitamin takviyesinin ortalama doğum ağırlığında ve LGA olan fetüsların insidansında artışa sebep olduğu, SGA ve düşük doğum ağırlıklı fetüsların insidansında düşüş gösterilmiştir (31). Bu çalışmada da multivitamin kullanan gebelerde LGA daha fazla görüldü ancak SGA ve düşük doğum ağırlığı ile mikro besin takviyesi arasında bir ilişki saptanmad1.

Amerika Birleşik Devletlerinde on iki ayrı merkezde yapılan çalışmada annenin serum 25(OH)D vitamin düzeyinin $37.5 \mathrm{nmol} / \mathrm{L}$ üstünde olanlarda bebeklerinin doğum ağırlığı, serum vitamin düzeyi düşük olanlara göre ortalama 46 gr daha kilolu olduğu ve ilk trimesterlerinde bu düzeyde olanların fetuslarında SGA olasığının \%50 azaldığı gösterildi. $\mathrm{Bu}$ çalışmada düşük doğum ağırlığı, SGA ile vitamin ve mineral kullanımı arasında fark saptanmadı.

Zarean ve Tarjan' in 180 gebe ile yaptıkları çalışmada Mg kullanan hastalarda preterm doğum, düşük doğum ağırlığı, doğum ağırlığı, GDM ve preeklampsi arasında kontrol grubu ve multivitamin kullanan gruba göre istatistiksel anlamlı ilişki bulunmuş (15). Gebelik boyunca $\mathrm{Ca}$ alan gebelerle yapilan bir meta-analizde ise Ca kullananlarda gebeliğe bağlı hipertansif hastalıkların gelişiminde $\% 45$ azalma olduğu gösterilmiş (32). On üç çalışmadan derlenen 15730 gebenin dahil olduğu bir Cochrane derlemesinde Ca mikro besin takviyesi alan grupta ortalama preeklampsi riskinin azaldığını ve etkinin düşük bazal Ca alımı olan kadınlarda en yüksek olduğu bildirmiştir (28). D vitamininin anjiogenez, immunmodulatör ve oksidatif streste oynadığ 1 rol üzerinden preeklampsiyle ilişkisi olduğu düşünülmektedir. Fakat D vitamini desteği preeklampsi riskini azaltmamakla birlikte, eksikliği preeklampsi riskini artırmaktadır (33). D vitamini ile GDM arasındaki ilişkiyi ortaya koymak amacıyla yapılan 1873 gebenin dahil edildiği çalışmada D vitamini eksikliğinin GDM riskini artırdığı gösterilmiş (34). Fakat az sayıda hasta ile yapılan üç randomize klinik çalışmanın meta-analizinde GDM'nin önlenmesinde D vitamini desteğinin yararı olmadığ1 gösterilmiştir, gebelik boyunca aşırı kilo alımının D vitamini eksikliğine sebep olacağı gibi faktörler göz önünde bulundurulmamıştır (35). Bu çalışmada $\mathrm{Mg}, \mathrm{Ca}$, D vitamini ve multivitamin kullananımı ile gebelik komplikasyonları arasında anlamlı ilişki bulunamadi. Bunun sebepleri arasında gebelerin bazal vitamin düzeylerinin bilinmemesi, aldığımız popülasyonun yaşam tarzının ve beslenme alışkanlıklarının birbirinden farklı olması, gruplardaki hasta sayısının eşit olmaması gibi nedenler sayılabilir. Bu çalışmaya dahil edilen hasta popülasyonun obstetrik öyküleri aynı olsa da (daha önce bir doğum yapmış ve ikinci gebeliğini yaşayan hastalar) hasta gruplarının sayısının eşit olmaması, demografik olarak heterojen bir gruptan oluşan çalışma popülasyonu olması ve en önemlisi mikro besin takviyesi kullanmayan bir kontrol grubunun olmamas1 çalışmamızı kısıtlayan faktörlerdir.

Literatürde birbiriyle çelişkili yazılar olsa da vitamin ve mineral desteğinin gösterilmiş yararları göz ardı edilemez. Annenin sağlıklı bir gebelik geçirmesi, maternal komplikasyonlardan korunmas1, fetusun büyüme ve gelişmesi için annenin düzenli beslenmesinin yanı sıra vitamin ve mineral takviyesi önemlidir. Bu takviyelerin literatürde gösterilmiş olan yararlarını desteklemek ve rutin kullanımda yer vermek için daha çok prospektif çalışmaya ihtiyaç vardır.

\section{KAYNAKLAR}

1. Wamberg L., Christiansen T., Paulsen SK., Fisker S., Rask P., Rejnmark L., et all. Expression of vitamin D-metabolizing enzymes in human adipose tissue - the effect of obesity and diet-induced weight loss. Int J Obes (Lond) 2013; 37:651-7.

2. Bener A., Al-Hamaq AO., Saleh NM. Association between vitamin D insuffi- ciency and adverse pregnancy outcome: global comparisons. Int $J$ Womens Health 2013; 5:523 - 531 .

3. Ma R., Gu Y., Zhao S, Sun J., Groome LJ., Wang Y. Expressions of vitamin D metabolic components VDBP, CYP2R1, CYP27B1, CYP24A1, and VDR in placentas from normal and preeclamptic pregnancies. Am J Physiol Endocri- nol Metab 2012;303:E928-35.

4. Imdad A., Jabeen A., Bhutta ZA. Role of calcium supplementation during preg-nancy in reducing risk of developing gestational hypertensive disorders: a meta-analysis of studies from developing countries. BMC Public Health. 2011; 11(Suppl 3):S18.

5. Fall CH., Fisher DJ., Osmond C., Margetts BM. Multiple micronutrient supplementation during pregnancy in low-income countries: a meta-analysis of effects on birth size and length of gestation. Food Nutr Bull, 30 (2009), pp. S533-S546.

6. Haider BA., Bhutta ZA. Multiple-micronutrient supplementation for women during pregnancy. Cochrane Database Syst Rev, 2015, 11.4.

7. Buppasiri P., Lumbiganon P., Thinkhamrop J., Ngamjarus C., Laopaiboon M., Medley N. Calcium supplementation (other than for preventing or treating hypertension) for improving pregnancy and infant outcomes. The Cochrane Library, 2015.

8. Hofmeyr GJ., Atallah AN., Duley L. Calcium supplementation during pregnancy for preventing hypertensive disorders and related problems. Cochrane Data- base Syst Rev. 2006;(3):CD001059.

9. Ortega RM., Martinez RM., Lopez-Sobaler AM., Andres P., Quintas ME. Influence of calcium intake on gestational hypertension. Annals of Nutrition and Metabolism 1999; 43:37-46.

10. Hsu WY., Wu CH., Hsieh CT., Lo HC., Lin JS., Kao MD. Low body weight gain, low white blood cell count and high serum ferritin as markers of poor nutrition and increased risk for preterm delivery. Asia Pac J Clin Nutr. 2013;22:90-99.

11. Uludag EU, Gozukara IO, Kucur SK, Ulug P., Ozdegirmenci O., Erkaya S. Maternal magnesium level effect on pre- term labor treatment. J Matern Fetal Neonatal Med. 2014;27:1449-1453.

12. Mercer BM., Merlino AA. Magnesium sulfate for preterm labor and preterm birth. Obstet Gynecol. 2009;114:650-668.

13. Goldenberg RL, Culhane JF, Iams JD, Romero R. Epidemiology and causes of preterm birth. Lancet. 2008;371:75-84.

14. Darnton-Hill I., Webb P., Harvey PWJ., Hunt JM., Dalmiya N., Chop- 
ra M., et all. Micronutrient deficiencies and gender: Social and economic costs. Am. J. Clin. Nutr. 2005, 819, 1198S-1205S.

15. Darnton-Hill I., Mkparu UC. Micronutrients in pregnancy in low-and middle-income countries. Nutrients, 2015, 7.3: 1744-1768.

16. Bhutta ZA., Haider BA. Prenatal micronutrient supplementation: Are we there yet? CMAJ 2009, 180, 1188-1189.

17. Gardosi J., Mongelli M., Wilcox M., Chang A. An adjustable Fetal Weight Standard. Ultrasound Obstet Gynecol 1995; 6: 168-74.

18. Sibai BM. Diagnosis and management of gestational hypertension and preeclampsia. Obstet Gynecol. 2003;102(1):181-192.

19. World Health Organization. Definition, Diagnosis and Classification of Diabetes Mellitus and Its Complications: Report of a WHO Consultation Part 1: Diagnosis and Classification of Diabetes Mellitus, 2nd ed. Geneva, Switzerland: World Health Organization; 1999. (WHO/NCD/NCS/99).

20. Arikan G., Guecer F., Schoell W., Weiss P. Preterm labour during oral magnesium supplementation in uncomplicated pregnancies. Geburtshilfe Frauenheilkd.1997;57:491-5.

21. Zarean E., Tarjan A. Effect of magnesium supplement on pregnancy outcomes: a randomized control trial. Advanced biomedical research, 2017, 6 .

22. Wynn A, Wynn M. Magnesium and other nutrient de ciencies as possible causes of hypertension and low birthweight. Nutr Health 1988;6:69-88.

23. Becker W, Lyhne N, Pedersen AN, Aro A, Fogelholm M, Phorsdottir I, et all. Nordic nutrition recommendations 2004-integrating nutrition and physical activity. Scand J Nutr 2004;48:178-87.

24. Jahnen-Dechent W, Ketteler M. Magnesium basics. Clin Kidney J. 2012;5(suppl 1):i3-i14.

25. McNamara HC, Crowther CA, Brown J. Different treatment regimens of magnesium sulphate for tocolysis in women in preterm labour. Cochrane Database Syst Rev 2015;12:CD011200.
26. Villar J., Belizan J., Fisher P. Kalsiyum alımı ve eklampsi arasındaki ilişsi üzerine epidemiyolojik gözlem. Uluslararası Jinekoloji ve Obstetrik Dergisi $1983 ; 21: 271-278$.

27. Yeşiltepe-Mutlu G., Hatun Ş. Perinatal D vitamini yetersizliği. Çocuk Sağlığl ve Hastalıkları Dergisi 2011; 54: 87-98

28. Kovacs, Christopher S. Calcium and bone metabolism disorders during pregnancy and lactation. Endocrinology and Metabolism Clinics, 2011. 40.4: $795-826$

29. TC Sağlık Bakanlı̆̆l. Gebelere D Vitamini Destek Programı: http:// www.saglik.gov.tr/TR/belge/1-12656/ gebelere-d-vitamini-destek-programi.html 1 Ocak 2011

30. Pérez-López FR., Pasupuleti V., Mezones-Holguin E., Benites-Zapata $V A$., Thota P., Deshpande A. et all. Effect of vitamin D supplementation during pregnancy on maternal and neonatal outcomes: a systematic review and meta-analysis of randomized controlled trials. Fertility and sterility, $2015,103.5: 1278-1288$ e 4 .

31. Gustafsson MK., Romundstad PR., Stafne SN., Helvik AS., Stunes AK., Mørkved S., et all. Alterations in the vitamin D endocrine system during pregnancy: A longitudinal study of 855 healthy Norwegian women. PloS one, 2018, 13.4: e0195041.

32. Brannon PM. Vitamin D and adverse pregnancy outcomes: beyond bone health and growth. Proc Nutr Soc 2012; 71:205 - 212.

33. Institute of Medicine. Report at a Glance, Report Brief: Dietary reference intakes for calcium and vitamin D, released 11/30/2010. Http://www. iom.edu/Reports/2010/Dietary-Reference-Intakes-for-Calcium-and-Vitamin-D/Report-Brief.aspx (Accessed on December 01, 2010).

34. De-Regil, L. M., Palacios, C., Lombardo, L. K., \& Peña-Rosas, J. P. Vitamin D supplementation for women during pregnancy. Sao Paulo Medical Journal, 2016, 134.3: 274-275.

35. ACOG Committee on Obstetric Practice. ACOG Committee Opinion No. 495: Vitamin D: Screening and supplementation during pregnancy. Obstet Gynecol 2011; 118:197. Reaffirmed 2017. 